\title{
Islet $\beta$-Cell Function Following 4.4-Year Insulin Injection in Chinese Elderly Patients with Type 2 Diabetes Mellitus
}

Wei Ling ( $\square$ lingwei19901016@163.com )

Guilin Medical University https://orcid.org/0000-0002-6923-2200

HUANG Yi

Guilin Medical University

XIAO Yan-Hua

Guilin Medical University

HUANG Yan-Mei

Fudan University

OU Yang-Fu

Guilin Medical University

HONG Xue-Zhi

Guilin Medical University

ZHAO Hai-Lu

Guilin Medical University

Original investigation

Keywords: Type 2 diabetes, Elderly patients, $\beta$-Cell function, Insulin

Posted Date: March 9th, 2020

DOI: https://doi.org/10.21203/rs.3.rs-16319/v1

License: (9) This work is licensed under a Creative Commons Attribution 4.0 International License.

Read Full License 


\section{Abstract}

Background The aim of this study was to scrutinize changes of islet $\beta$-cell function in Chinese elderly patients with type 2 diabetes mellitus (T2DM) after insulin versus oral anti-diabetic (OAD) treatments.

Methods In this prospective study, islet $\beta$-cell function was determined by oral glucose tolerance testderived fasting C-peptide, maximal C-peptide, C-peptide area under the curve (AUC c-pep) and fasting cpep /fasting glu , maximal c-pep /maximal glu , AUC c-pep /AUC glu . Differences in $\beta$-cell function indices between baseline and follow-up were compared among insulin monotherapy, OAD monotherapy and combined therapies.

Results From 2009 to 2017, 419 elderly patients (men: 51.1\%) with T2DM (insulin monotherapy, n=105; OAD monotherapy, $n=172$; insulin $+O A D, n=142$ ) had undergone baseline and follow-up $\beta$-cell function assessment after a mean observation of 4.4 (range, 3.0 - 7.2) years. Overall, islet $\beta$-cell function indices were decreased in all the three groups: insulin (fasting C-peptide: $p=0.002$; maximal C-peptide: $p=0.005$; fasting c-pep /fasting glu : $p=0.015$; maximal c-pep /maximal glu : $p=0.031$ ), OAD (fasting C-peptide: $p=0.026$; maximal C-peptide: $p=0.013$; fasting c-pep /fasting glu : $p=0.025$; maximal c-pep /maximal glu : $p=0.029$ ), insulin + OAD (fasting C-peptide: $p<0.001$; maximal C-peptide: $p<0.001$; fasting c-pep /fasting glu : $p=0.015$; maximal c-pep /maximal glu $: p=0.019)$. No significant differences of reduction were observed among the three groups regarding the fasting $C$-peptide $(p=0.437)$, fastingc-pep/fastingglu $(p=0.598)$, maximalc-pep/maximalglu ( $p=0.756)$, AUCc-pep $(p=0.856)$ and AUCc-pep/AUCglu $(p=0.912)$. However, the OAD treatment group had showed a less reduction level over insulin or insulin + OAD treatment.

Conclusions In Chinese elderly patients with T2DM, islet $\beta$-cell function indices progressively decline regardless of insulin supplement or insulin plus OAD treatments. However, patients with OAD monotherapy may provide better $\beta$-cell function preservation than the insulin treatments.

\section{Background}

The effect of insulin therapy for islet $\beta$-cell function in patients with type 2 diabetes mellitus (T2DM) remains inconclusive. The United Kingdom Prospective Diabetes Study (UKPDS) has clearly showed that islet $\beta$-cell function deteriorates over time irrespective of any glucose lowering modalities, including exogenous insulin. ${ }^{1-3}$ Whereas results from more recently studies by Weng et al. and others showed that short-term exogenous insulin intervention has favorable outcomes on the maintenance of $\beta$-cell function and the remission of hyperglycemia in adult T2DM patients. ${ }^{4-6}$ Recently, the Restoring Insulin Secretion (RISE) Adult Medication Study has disclosed that early intervention with insulin glargine was not associated with any improvement in $\beta$-cell function in youth with impaired glucose tolerance (IGT) or early diagnosed T2DM ${ }^{7}$. Furthermore, the RISE Pediatric Medication Study also revealed that all $\beta$-cell measures at 12 months and 15 months were worse than baseline in youth with IGT or recently diagnosed 
$\mathrm{T}^{2} \mathrm{DM}{ }^{8}$. These different findings might have affected the clinical choices of treatment modalities, and how to preserve islet $\beta$-cell function in patients with T2DM remains an essential question.

The reason for these controversial opinions remains unclear, yet age may play an essential role regarding the effect of insulin therapy on $\beta$-cell function. Noteworthy, across the spectrum of T2DM patients, elderly people have the highest prevalence. ${ }^{9}$ It is reported that more than $25 \%$ of adults older than 65 years of age in the United States have diabetes. ${ }^{10}$ Elderly patients with T2DM are at higher risk of diabetic complications and pose heavier burden on health care systems and social economics. ${ }^{11,12}$ However, no studies have yet evaluated the effect of insulin therapy on $\beta$-cell function in an exclusively elderly population. Considering that the majority of T2DM patients are old people, and that T2DM in these older individuals represents a more severe and rapidly progressive condition than their young adult counterparts, it is of particular importance to better understand the effect of insulin therapy on islet $\beta$-cell function in these populations. In this study, we scrutinize the changes of $\beta$-cell function in Chinese elderly patients with T2DM after insulin and oral anti-diabetic therapies.

\section{Methods}

\section{Participants}

We included clinically diagnosed T2DM patients aged 65 years and older since January 2009 from the Endocrinology Department of the Affiliated Hospital of Guilin Medical University. The diagnostic criteria were based on the WHO diagnostic criteria (1999). All newly diagnosed patients were naïve to any antihyperglycemia therapies while the previous diagnosed patients had been treated with glucose lowering regimens including exogenous insulin, OAD or combined. Patients were included if they were T2DM patients older than 65 years. Patients were excluded if they were T1DM patients or had acute or severe chronic diabetic complications, critical illnesses or malignancies. The T2DM diagnosis secondary to other diseases such as Cushing syndrome or pancreatic diseases was also excluded. The research ethic board of the Guilin Medical University approved this study. All patients gave written informed consent before treatment.

\section{Study design}

This is a prospective study. Patients were treated with standard glucose lowering regimens to reach fasting glucose between 6.5 to $7.5 \mathrm{mmol} / \mathrm{L}$ using exogenous insulin, OAD or both by our diabetologists according to the guidelines. According to their prescriptions, we divided the patients into three groups: (1) insulin monotherapy; (2) OAD monotherapy; and (3) combined therapy with both insulin and OAD. Islet $\beta$ cell function was compared between before and after treatment in each group. For patients with the OAD monotherapy, those with a body-mass index (BMI) level of less than $25 \mathrm{~kg} / \mathrm{m} 2$ were initially treated with sulfonylurea drugs, acarbose or pioglitazone while those with BMI higher than $25 \mathrm{~kg} / \mathrm{m} 2$ were initially treated with metformin. Patients were initially treated with single OAD, a combination of different OADs 
was used in patients who could not maintain euglycemia. Patients received insulin monotherapy were treated by pre-meal insulin aspart or insulin detemir at bedtime using multiple daily insulin injections. The doses of insulin or OAD were prescribed by our diabetologists based on the patients' glucose level and body weight. If the treatments with monotherapy still failed to achieve the target glucose level (fasting glucose between $6.5 \mathrm{mmol} / \mathrm{L}$ to $7.5 \mathrm{mmol} / \mathrm{L}$ ), the $O A D$ or exogenous insulin would be added subsequently. All patients received diabetic education and were told to take adequate exercise and healthy diet. During the observation, patients were told to monitor their glucose everyday at home. All patients were provided with access to reach the diabetologists anytime for consultation.

\section{$\beta$-Cell function indices and other laboratory measurements}

A standard questionnaire was administered by our trained staff to record patients' demographic and clinical data. After an overnight fast of 10 hours, venous blood samples were collected to measure fasting plasma glucose, fasting C-peptide, fasting insulin, $\mathrm{HbA} 1 \mathrm{c}$, lipid profiles, plasma creatinine and plasma urea. Blood samples were also drawn at 0,30,60,120 and 180 min after a $75 \mathrm{~g}$ glucose load to measure glucose, C-peptide, and insulin in all subjects. All hospitalized T2DM patients were routinely undergo oral glucose tolerance test (OGTT) to evaluate their $\beta$-cell function prior any treatments. Before OGTT, hypoglycemic treatments were withheld for 24 hours in order to washout drug effects. Islet $\beta$-cell function was determined by fasting C-peptide, maximal C-peptide fastingc-pep/fastingglu, maximalcpep/maximalglu, calculated C-peptide area under the curve (AUCc-pep) and AUCc-pep/AUCglu basing on the OGTT values by trapezoidal rule. Early phase of insulin secretion function was reflected by the Cpeptide index $(\triangle \mathrm{C} 30 / \Delta \mathrm{G} 30)$ and insulin peak time was compared between before and after treatment. Whole body insulin sensitivity and insulin resistance were also measured by Matsuda index $(\mathrm{MI}=$ $10000 /$ (mean glucose $\times$ mean insulin $\times$ fasting glucose $\times$ fasting insulin) 0.5 ) and Homeostasis Model Insulin Resistance (HOMA-IR $=20 \times$ Fasting insulin /[Fasting glucose -3.5$])$, respectively.

\section{Statistical analyses}

Data were presented as absolute number and percentage using SPSS 18.0 software (SPSS Corporation, Chicago, USA). Normally distributed and continuous variables were presented as mean \pm SD. Nonnormally distributed variables were presented as median with interquartile range (IQR), or presented as mean \pm SD after being log-transformed. The paired t-test or Wilcoxon matched paired test was used to assess the difference of variables between before and after intervention. Chi-squared tests were done to analyze categorical variables. One way analysis of variances (ANOVA) or Kruskal-Waillis test were used to analyze normally quantitative variables and non-normally distributed variables respectively in multiple comparisons. The comparisons of the changes of $\beta$-cell function among the three groups were also made using an analysis of covariance (ANCOVA) model with treatment as fixed effects and fasting C-peptide, 
age, sex, body-mass index, hypertension, triglycerides and plasma creatinine as covariates. Significance was defined as two tailed $p$ value less than 0.05 .

\section{Results}

\section{Participants' characteristics}

From January 2009 to December 2017, a total of 735 patients were initially enrolled into the study. Among them, 316 patients were excluded from final assessment because of lost to followed-up, miss $\beta$ cell function evaluation and incomplete values in variables used. Finally, 419 elderly T2DM patients (mean age: $68.8 \pm 5.8$ years; men: $45.0 \%$ ) who had baseline and follow-up $\beta$-cell function assessment were included. Mean followed-up duration were 4.4 years (3-7.2 years). Among them, 158 were newly diagnosed while 261 were previously diagnosed (mean disease duration: 3.2 years). Table 1 shows the demographic and metabolic characteristics of the patients receiving insulin monotherapy $(n=105), O A D$ monotherapy $(n=172)$, and combined therapy $(n=142)$. Overall, the OAD group had significantly lower diastolic blood pressure, plasma urea and creatinine, fasting glucose, 2-hour postprandial glucose, and $\mathrm{HbA1c}$, while higher level of triglycerides, fasting insulin, fasting C-peptide, and HOMA- $\beta$. Significant differences in other baseline measurements were found among the three groups.

\section{Changes of $\beta$-cell function}

Insulin secretion, as measured by fasting C-peptide, maximal C-peptide, fastingc-pep/fastingglu, maximalc-pep/maximalglu, AUCc-pep and AUCc-pep/AUCglu, were all significantly higher in the OAD group than the insulin group and insulin plus OAD group (all $p<0.001$ ) at baseline. After $4.4(3.0$ - 7.2$)$ years of treatment, these indices in OAD group were also the highest among the three groups. Table 2 shows the glycemic and $\beta$-cell function indices among the three groups. When comparing $\beta$-cell function before and after treatment, a significantly decreased level of fasting C-peptide, maximal C-peptide, fastingc-pep/fastingglu, or maximalc-pep/maximalglu was observed in the three groups: insulin group (fasting C-peptide: $p=0.002$; maximal C-peptide: $p=0.005$; fastingc-pep/fastingglu: $p=0.015$; maximalcpep/maximalglu: $p=0.031$ ), OAD group (fasting C-peptide: $p=0.026$; maximal C-peptide: $p=0.013$; fastingcpep/fastingglu: $p=0.025$; maximalc-pep/maximalglu: $p=0.029$ ), insulin plus $O A D$ group (fasting $C$ peptide: $p<0.001$; maximal C-peptide: $p<0.001$; fastingc-pep/fastingglu: $p=0.015$; maximalcpep/maximalglu: $p=0.019$ ). The AUCc-pep was significantly decreased in the insulin plus OAD group $(p=0.047)$. No significant changes of AUCc-pep were observed in the insulin group $(p=0.153)$ or OAD group $(p=0.294)$ and no significant changes of AUCc-pep/AUCglu were observed in all groups (all $p>0.05)$. 
No significant differences of reduction were observed among the three groups regarding the fasting $\mathrm{C}$ peptide $(p=0.437)$, fastingc-pep/fastingglu $(p=0.598)$, maximalc-pep/maximalglu $(p=0.756)$, AUCc-pep $(p=0.856)$ and AUCc-pep/AUCglu $(p=0.912)$. However, the maximal $C$-peptide in the OAD group $(p=0.021)$ had showed a significant less reduction than the other two groups. Moreover, although no significant reduction of most $\beta$-cell function indices were observed among the three groups, the OAD treatment group had showed a less reduction level over insulin or insulin plus OAD treatment (Figure 1).

\section{Initial phase of insulin secretion and peak insulin secretion}

The early phase of insulin secretion reflected by the $\triangle \mathrm{C} 30 / \triangle \mathrm{G} 30$ was significantly higher in OAD group than insulin group and insulin plus OAD group in both before and after treatment (Table 2). However, there were no obvious changes regarding $\triangle \mathrm{C} 30 / \triangle \mathrm{G} 30$ between before and after 4.4 years of treatment among the three groups (insulin: $p=0.348 ; O A D: p=0.201$; both: $p=0.368$ ). We also calculated the changes of insulin peak time between before and after observation. As shown in Figure 2, peak insulin was postponed in the three groups after 4.4 years of observation. The percentage of participants whose insulin peak time were shorter than 1 hour was reduced (insulin: $16 \%$ to 10\%; OAD: $22 \%$ to $13 \%$; insulin plus OAD: $17 \%$ to $6 \%$ ) while those longer than 1 hour was increased (insulin: $84 \%$ to $90 \%$; OAD: $78 \%$ to $87 \%$; insulin plus OAD: $83 \%$ to $94 \%$ ).

\section{Insulin resistance indices}

The whole body insulin sensitivity and insulin resistance measured by Matsuda index and HOMA-IR were also shown in Table 2. There were no significant differences between before and after treatment regarding the Matsuda index and HOMA-IR in all the three groups (all $p>0.05$ ).

\section{Discussion}

In this prospective study, we have demonstrated that islet $\beta$-cell function in elderly patients with T2DM significantly declined independent of anti-diabetic therapy by insulin, OAD or combination after a mean observation of 4.4 years. Furthermore, patients used insulin or insulin plus OAD had relatively accelerated $\beta$-cell function reduction. To our knowledge, this is the first study highlighting the effect of different antidiabetic regimens on islet $\beta$-cell function in an exclusive population of elderly T2DM patients.

Islet $\beta$-cell function preservation is an important issue in the treatment of T2DM. Previously, many studies had come up with inconsistent conclusions (both positive, neutral or negative) regarding the effect of anti-diabetic therapies on $\beta$-cell function preservation. ${ }^{4,7,13}$ However, most of the positive effects diminished or even lower than the baseline after drugs withhold. ${ }^{14-16}$ Moreover, most current available studies which assessed the $\beta$-cell function preservation had focused on middle-age population. For example, the UKPDS enrolled participants aged 25 to 65 years old and concluded that pancreatic $\beta$-cell function in patients with T2DM deteriorates over time, leading to worsening metabolism and increasingly anti-diabetic requirements. ${ }^{13}$ Studies by Weng and colleagues studied patients with a mean age of $50.0 \pm$ 10.5 years old and found that insulin therapy in newly diagnosed T2DM patients had a favorable effect 
on the $\beta$-cell cell function preservation. ${ }^{4} A$ meta-analysis which summarized seven studies of postintensive insulin therapy for patients with T2DM showed an increase in HOMA- $\beta$ as compared with baseline. Notably, all of the included studies recruited participants within the age between 45.8 and 58.7 years. ${ }^{5}$ The RISE study had studied a group of young onset patients with newly-diagnosed or IGT and demonstrated that treatment with glargine or metformin in these patients dose not halt the progressive deterioration of $\beta$-cell cell function. ${ }^{7,8}$ Currently, studies on $\beta$-cell function in an exclusively elderly population are valuable. In this study, we have shown the changes of $\beta$-cell function treated with different glucose lowering regimens in elderly T2DM patients. Results showed that the $\beta$-cell function deteriorates in all treatment modalities independent of the insulin therapies, indicating that $\beta$-cell function in these populations may distinctly differ from their young counterparts. This phenomenon, on one hand, can be largely attributed to ageing per se. The age-related impairment of $\beta$-cell function has been linked to many factors such as mitochondrial dysfunction; ${ }^{17,18}$ reduced GLUT2 levels; ${ }^{19}$ impaired $\mathrm{Ca}++$ handling; ${ }^{20}$ increased autophagy; ${ }^{21}$ and reduced expression of beta-cell-specific genes and transcription factors. ${ }^{19}$ Since ageing carries additional risks for $\beta$-cell dysfunction and insulin resistance, it is challenging to halt the deterioration of $\beta$-cell function in elderly T2DM patients.

In this study, we also found that patients with OAD treatment had less $\beta$-cell function reduction over insulin or insulin plus OAD treatment, indicating that OAD treatment may provide better $\beta$-cell function preservation, although these did not reach statistical significance because of the relatively small sample sizes. Such results can be ascribed to the worse baseline $\beta$-cell function in insulin group and insulin plus OAD group while the better baseline $\beta$-cell function in OAD monotherapy group. Firstly, patients who take insulin plus OAD therapy had a higher level of fasting glucose, postprandial glucose and $\mathrm{HbA1 \textrm {C }}$ at both baseline and follow-up, indicating that these patients are more prone to be encountered with glucotoxicity, which is known to be associated with poor $\beta$-cell function preservation. ${ }^{22}$ Additionally, some patients in the insulin plus OAD group only had OAD monotherapy or insulin monotherapy at the beginning of the study, however, they received one more therapy due to uncontrolled hyperglycemia during follow up. These results demonstrated that such patients had worse glycemic variability, which is both a cause and consequence for poor $\beta$-cell function. ${ }^{23-25}$ Thirdly, better $\beta$-cell function preservation in patients with OAD monotherapy may due to better baseline $\beta$-cell function, since worse baseline $\beta$-cell function per se is associated with worse metabolic control and higher hyperglycemia or hypoglycemia events. ${ }^{26}$

Of note, unlike many studies which showed a protective effect of insulin therapies or insulin plus OAD for $\beta$-cell function preservation, ${ }^{5,27}$ outcomes in this study demonstrated that $\beta$-cell function deteriorates irrespective of the insulin therapies in elderly T2DM patients. This phenomenon can be ascribed to the following reasons. On one hand, observation period in the present study had last for a mean duration of 4.4 years, which is much longer than previous studies that had demonstrated favorable effects of insulin therapy for $\beta$-cell preservation. ${ }^{5}$ It remains unknown if the positive effects in those studies persist or not after 4.4 years of observation. On the other hand, more than $60 \%$ of the included participants in this study had mean disease duration about 3 years. Moreover, even the newly diagnosed T2DM patients in elderly may also suffer long-term diabetic duration at the time of diagnosis. Therefore, the mass of beta cell, the 
capacity of $\beta$-cell function, the insulin sensitivity and the response ability to hypoglycemic regimens may be accelerated than the middle-age early-staged patients. Lastly, long duration of insulin treatment may provide rigorous glycemic control, however, long-term exogenous insulin exposure in elderly may have also led to additional adverse effects such as weight gain, insulin resistance and hypoglycemia events, ${ }^{28,}$

${ }^{29}$ which may offset the benefit of insulin-induced euglycemia and add extra burden to $\beta$-cell cell function. Therefore, insulin intervention in this population may pose an uncertain net balance of benefit and harm for $\beta$-cell cell function.

There are limitations in this study. First, the present study is an observational study rather than a randomized control trial. Second, we could not include placebo arm since it is unethical for elderly T2DM patients if left untreated. Third, $62.3 \%$ of the 419 patients in this study were not newly diagnosed, therefore, we could not assess the baseline $\beta$-cell function that is really before treatment in these patients. Last, this study was conducted in a single (Asian) racial group and that the results may not be generalizable to other groups. Nevertheless, findings in this study highlight that insulin administration may not preventive for $\beta$-cell function deterioration in the elderly T2DM patients. Since old people may differ distinctly from the middle-aged or young population in both physiology and pathophysiology, furthermore, there is also extensive variability within T2DM population in terms of clinical presentation, psychosocial environment, and resource availability. Therefore, it is difficult to delay the inexorable decline of $\beta$-cell function through single pharmacological agents. The management of $\beta$-cell dysfunction in elderly should be individualized that taking multiple factors into consideration such as living situation, overall health, cognitive functions and the presence of comorbidities.

\section{Conclusion}

Results in this study reveal that the $\beta$-cell function in elderly T2DM patients declines over time independent of insulin or OAD treatments, however, patients with OAD treatment may provide better $\beta$-cell function preservation than the insulin treatments.

\section{Abbreviations}

Type 2 diabetes mellitus (T2DM); oral anti-diabetic (OAD); area under the curve (AUC); United Kingdom Prospective Diabetes Study (UKPDS); Restoring Insulin Secretion (RISE); impaired glucose tolerance (IGT); body-mass index (BMI); oral glucose tolerance test (OGTT); Homeostasis Model Insulin Resistance (HOMA-IR); One way analysis of variances (ANOVA); analysis of covariance (ANCOVA); Standard deviance (SD)

\section{Declarations}

\section{Ethics approval and consent to participate}

The research ethic board of the Guilin Medical University approved this study. 


\section{Consent for publication}

Not applicable.

\section{Availability of data and materials}

Data may be available from the authors upon reasonable request and with explicit permission from Guilin Medical University.

\section{Competing interests.}

The authors declare that they have no competing interests.

\section{Authors' contributions.}

The conception and design of the study, and draft of this manuscript were performed by ZHL and LW. The generation and data collection were performed by HXZ, XYH and OYF. The assembly and analysis and/or interpretation of the data were performed by HY and HYM. All authors read and approved the final manuscript.

\section{Acknowledgements and Funding.}

This work was supported by a grant from the National Natural Science Foundation of China (81471054) and the Innovation Project of Guangxi Graduate Education (JGY2015128). The funders had no role in the study design, data collection and analysis, decision to publish, or preparation of the manuscript.

\section{References}

[1] U.K. prospective diabetes study 16. Overview of 6 years' therapy of type II diabetes: a progressive disease. U.K. Prospective Diabetes Study Group. Diabetes. 1995; 44: 1249-1258.

[2] Turner RC, Cull CA, Frighi V, Holman RR. Glycemic control with diet, sulfonylurea, metformin, or insulin in patients with type 2 diabetes mellitus: progressive requirement for multiple therapies (UKPDS 49). UK Prospective Diabetes Study (UKPDS) Group. JAMA. 1999; 281: 2005-2012.

[3] Nolan CJ, Damm P, Prentki M. Type 2 diabetes across generations: from pathophysiology to prevention and management. Lancet. 2011; 378: 169-181.

[4] Weng J, Li Y, Xu W, et al. Effect of intensive insulin therapy on beta-cell function and glycaemic control in patients with newly diagnosed type 2 diabetes: a multicentre randomised parallel-group trial. Lancet. 2008; 371: 1753-1760.

[5] Kramer CK, Zinman B, Retnakaran R. Short-term intensive insulin therapy in type 2 diabetes mellitus: a systematic review and meta-analysis. Lancet Diabetes Endocrinol. 2013; 1: 28-34. 
[6] Hu Y, Li L, Xu Y, et al. Short-term intensive therapy in newly diagnosed type 2 diabetes partially restores both insulin sensitivity and beta-cell function in subjects with long-term remission. Diabetes Care. 2011;

34: 1848-1853.

[7] Consortium R. Lack of Durable Improvements in beta-Cell Function Following Withdrawal of Pharmacological Interventions in Adults With Impaired Glucose Tolerance or Recently Diagnosed Type 2 Diabetes. Diabetes Care. 2019; 42: 1742-1751.

[8] Consortium R. Impact of Insulin and Metformin Versus Metformin Alone on beta-Cell Function in Youth With Impaired Glucose Tolerance or Recently Diagnosed Type 2 Diabetes. Diabetes Care. 2018; 41: 17171725.

[9] Collaboration NCDRF. Worldwide trends in diabetes since 1980: a pooled analysis of 751 populationbased studies with 4.4 million participants. Lancet. 2016; 387: 1513-1530.

[10] Kirkman MS, Briscoe VJ, Clark N, et al. Diabetes in older adults. Diabetes Care. 2012; 35:2650-2664.

[11] Leung E, Wongrakpanich S, Munshi MN. Diabetes Management in the Elderly. Diabetes Spectr. 2018; 31: 245-253.

[12] American Diabetes A. Economic Costs of Diabetes in the U.S. in 2017. Diabetes Care. 2018; 41: 917928.

[13] Intensive blood-glucose control with sulphonylureas or insulin compared with conventional treatment and risk of complications in patients with type 2 diabetes (UKPDS 33). UK Prospective Diabetes Study (UKPDS) Group. Lancet. 1998; 352: 837-853.

[14] Kahn SE, Haffner SM, Heise MA, et al. Glycemic durability of rosiglitazone, metformin, or glyburide monotherapy. N Engl J Med. 2006; 355: 2427-2443.

[15] Bunck MC, Diamant M, Corner A, et al. One-year treatment with exenatide improves beta-cell function, compared with insulin glargine, in metformin-treated type 2 diabetic patients: a randomized, controlled trial. Diabetes Care. 2009; 32: 762-768.

[16] Retnakaran R, Kramer CK, Choi H, Swaminathan B, Zinman B. Liraglutide and the preservation of pancreatic beta-cell function in early type 2 diabetes: the LIBRA trial. Diabetes Care. 2014; 37: 3270-3278.

[17] Liesa M, Shirihai OS. Mitochondrial dynamics in the regulation of nutrient utilization and energy expenditure. Cell Metab. 2013; 17: 491-506.

[18] Barzilai N, Huffman DM, Muzumdar RH, Bartke A. The critical role of metabolic pathways in aging. Diabetes. 2012; 61: 1315-1322. 
[19] Ihm SH, Moon HJ, Kang JG, et al. Effect of aging on insulin secretory function and expression of beta cell function-related genes of islets. Diabetes Res Clin Pract. 2007;77 Suppl 1: S150-154.

[20] Ribeiro RA, Batista TM, Coelho FM, Boschero AC, Lopes GS, Carneiro EM. Decreased beta-cell insulin secretory function in aged rats due to impaired $\mathrm{Ca}(2+)$ handling. Exp Physiol. 2012; 97: 1065-1073.

[21] Wang S, Sun QQ, Xiang B, Li XJ. Pancreatic islet cell autophagy during aging in rats. Clin Invest Med. 2013; 36: E72-80.

[22] Poitout V, Robertson RP. Glucolipotoxicity: fuel excess and beta-cell dysfunction. Endocr Rev. 2008; 29: 351-366.

[23] Kramer CK, Choi H, Zinman B, Retnakaran R. Glycemic variability in patients with early type 2 diabetes: the impact of improvement in beta-cell function. Diabetes Care. 2014; 37: 1116-1123.

[24] Ceriello A, Ihnat MA. 'Glycaemic variability': a new therapeutic challenge in diabetes and the critical care setting. Diabet Med. 2010; 27: 862-867.

[25] Siegelaar SE, Holleman F, Hoekstra JB, DeVries JH. Glucose variability; does it matter? Endocr Rev. 2010; 31: 171-182.

[26] Saisho Y, Tanaka K, Abe T, Kawai T, Itoh H. Lower beta cell function relates to sustainedhigher glycated albumin to glycated hemoglobin ratio in Japanese patients with type 2 diabetes. Endocr J. 2014; 61: 149-157.

[27] Mu PW, Chen YM, Lu HY, et al. Effects of a combination of oral anti-diabetes drugs with basal insulin therapy on beta-cell function and glycaemic control in patients with newly diagnosed type 2 diabetes. Diabetes Metab Res Rev. 2012; 28: 236-240.

[28] Balkau B, Home PD, Vincent M, Marre M, Freemantle N. Factors associated with weight gain in people with type 2 diabetes starting on insulin. Diabetes Care. 2014; 37: 2108-2113.

[29] Shorr RI, Ray WA, Daugherty JR, Griffin MR. Incidence and risk factors for serious hypoglycemia in older persons using insulin or sulfonylureas. Arch Intern Med. 1997; 157: 1681-1686.

\section{Tables}

Table 1. Baseline characteristics of included participants. 


\begin{tabular}{|c|c|c|c|c|}
\hline & Insulin & OAD & $\begin{array}{l}\text { Insulin + } \\
\text { OAD }\end{array}$ & value \\
\hline Patients (n) & 105 & 172 & 142 & \\
\hline Men (\%) & $52.40 \%$ & $52.30 \%$ & $48.60 \%$ & 0.529 \\
\hline Age (yr) & $67.4 \pm 6.7$ & $69.7 \pm 7.0$ & $68.8 \pm 6.7$ & $<0.001$ \\
\hline Duration (yr) & $3.4 \pm 0.9$ & $3.0 \pm 0.8$ & $3.2 \pm 0.6$ & 0.156 \\
\hline Body mass index $(\mathrm{kg} / \mathrm{m} 2)$ & $24.4 \pm 3.3$ & $24.4 \pm 3.3$ & $25.6 \pm 3.8$ & 0.289 \\
\hline Waist (cm) & $85.8 \pm 9.7$ & $85.7 \pm 10.4$ & $89.6 \pm 10.6$ & 0.176 \\
\hline SBP (mmHg) & $140.4 \pm 23.5$ & $140.5 \pm 23.6$ & $143.7 \pm 22.0$ & 0.261 \\
\hline $\mathrm{DBP}(\mathrm{mmHg})$ & $81.6 \pm 13.4$ & $75.7 \pm 11.8$ & $77.3 \pm 11.7$ & $<0.001$ \\
\hline Hypertension (\%) & $49.40 \%$ & $46.90 \%$ & $55.10 \%$ & 0.328 \\
\hline HbA1c (\%) & $9.1 \pm 3.0$ & $8.6 \pm 2.5$ & $9.7 \pm 2.7$ & 0.003 \\
\hline HDL-cholesterol (mmol/L) & $1.27 \pm 0.4$ & $1.24 \pm 0.35$ & $1.23 \pm 0.33$ & 0.738 \\
\hline LDL-cholesterol $(\mathrm{mmol} / \mathrm{L})$ & $3.72 \pm 1.19$ & $3.57 \pm 0.97$ & $3.42 \pm 0.9$ & 0.515 \\
\hline Total cholesterol $(\mathrm{mmol} / \mathrm{L})$ & $5.7 \pm 1.38$ & $5.59 \pm 1.17$ & $5.4 \pm 1.1$ & 0.525 \\
\hline Triglycerides (mmol/L) & $1.64 \pm 1.01$ & $1.83 \pm 1.48$ & $1.67 \pm 1.01$ & 0.018 \\
\hline Plasma creatinine $(\square \mathrm{mol} / \mathrm{L})$ & $\begin{array}{r}178.43 \pm \\
114.27\end{array}$ & $142.24 \pm 88.74$ & $\begin{array}{c}265.87 \pm \\
167.94\end{array}$ & $<0.001$ \\
\hline Plasma urea (mmol/L) & $6.0 \pm 3.8$ & $5.7 \pm 3.2$ & $6.4 \pm 3.9$ & 0.013 \\
\hline $\begin{array}{l}\text { Fasting plasma glucose } \\
(\mathrm{mmol} / \mathrm{L})\end{array}$ & $8.2 \pm 2.8$ & $7.7 \pm 3.0$ & $8.7 \pm 3.6$ & 0.017 \\
\hline $\begin{array}{l}\text { Fasting plasma insulin } \\
(\mathrm{pmol} / \mathrm{L})\end{array}$ & $43.6(27.4-78.3)$ & $52(33.6-84.9)$ & $46.1(22-83)$ & 0.401 \\
\hline $\begin{array}{l}\text { Fasting plasma C-peptide } \\
(\mathrm{nmol} / \mathrm{L})\end{array}$ & $0.65(0.49-0.96)$ & $0.8(0.50-0.1 .2)$ & $0.6(0.4-0.89)$ & 0.001 \\
\hline $\begin{array}{l}\text { 2-h plasma glucose } \\
(\mathrm{mmol} / \mathrm{L})\end{array}$ & $12.6 \pm 5.8$ & $12.5 \pm 4.7$ & $13.5 \pm 5.1$ & 0.008 \\
\hline
\end{tabular}




\begin{tabular}{|l|l|l|l|l|}
\hline 2-h plasma insulin (pmol/L) & $171.5(64.3-270$ & $250.6(148.7-429$ & $117.9(71-257)$ & 0.039 \\
\hline 2-h plasma C-peptide & 1 1) & $6)$ & & \\
\hline (nmol/L) & $1.46(0.78-2.11)$ & $1.64(1.2-2.2)$ & $0.76(0.45-1.29$ & $<0.001$ \\
\hline LN HOMA- $\beta$ & $5.47 \pm 1.07$ & $5.74 \pm 0.88$ & $5.37 \pm 1.27$ & 0.008 \\
\hline LN HOMA-IR & $2.62 \pm 1.11$ & $2.79 \pm 1.00$ & $2.64 \pm 1.25$ & 0.927 \\
\hline
\end{tabular}

Note: Data are presented as percent, mean \pm SD or median with interquartile range; $p$ value was derived from the Chi-squired test, One-Way ANOVA or Kruskal-Waillis test. OAD: oral anti-diabetes drugs; SBP: systolic blood pressure; DBP: diastolic blood pressure; HDL-C: high-density lipoprotein cholesterol; LDL-C: low-density lipoprotein cholesterol; HOMA, homeostasis model assessment; IR: insulin resistance

Table 2. Comparisons of glucose control and $\beta$-cell function at baseline and follow-up 


\begin{tabular}{|c|c|c|c|c|}
\hline & Insulin & $\mathrm{OAD}$ & Insulin + OAD & $\mathrm{p}$ value \\
\hline Patients (n) & 105 & 172 & 142 & \\
\hline \multicolumn{5}{|c|}{ Fastingglu (mmol/L) } \\
\hline Before & $8.2 \pm 2.8$ & $7.7 \pm 3.0$ & $8.7 \pm 3.6$ & 0.017 \\
\hline After & $8.1 \pm 3.3$ & $7.6 \pm 3.4$ & $9.1 \pm 4.2$ & 0.045 \\
\hline $\mathrm{p}$ value & 0.876 & 0.941 & 0.475 & \\
\hline \multicolumn{5}{|c|}{ Maximalglu (mmol/L) } \\
\hline Before & $12.6 \pm 5.8$ & $12.5 \pm 4.7$ & $14.5 \pm 5.9$ & 0.013 \\
\hline After & $13.8 \pm 5.2$ & $12.5 \pm 4.2$ & $13.5 \pm 5.1$ & 0.245 \\
\hline $\mathrm{p}$ value & 0.295 & 0.975 & 0.169 & \\
\hline \multicolumn{5}{|l|}{ HbA1c (\%) } \\
\hline Before & $9.1 \pm 3.0$ & $8.6 \pm 2.5$ & $9.7 \pm 2.7$ & 0.002 \\
\hline After & $8.2 \pm 2.3$ & $7.9 \pm 2.0$ & $9.3 \pm 2.3$ & $<0.001$ \\
\hline $\mathrm{p}$ value & 0.047 & 0.024 & 0.246 & \\
\hline \multicolumn{5}{|c|}{ AUCglu (mmol/L/h) } \\
\hline Before & $45 \pm 17.5$ & $43.2 \pm 15.4$ & $49.4 \pm 18.7$ & 0.017 \\
\hline After & $46.7 \pm 15.2$ & $42.6 \pm 12.8$ & $47.4 \pm 17.2$ & 0.085 \\
\hline $\mathrm{p}$ value & 0.621 & 0.758 & 0.384 & \\
\hline \multicolumn{5}{|c|}{ FastingC-pep (nmol/L/h) } \\
\hline Before & $0.65(0.49-0.96)$ & $0.8(0.50-1.2)$ & $0.6(0.4-0.89)$ & 0.001 \\
\hline After & $0.50(0.29-0.70)$ & $0.71(0.49-1.0)$ & $0.45(0.28-0.63)$ & $<0.001$ \\
\hline $\mathrm{p}$ value & 0.002 & 0.026 & $<0.001$ & \\
\hline \multicolumn{5}{|c|}{ FastingC-pep / Fastingglu } \\
\hline Before & $0.08(0.05-0.12)$ & $0.11(0.17-0.16)$ & $0.07(0.04-0.11)$ & $<0.001$ \\
\hline After & $0.05(0.03-0.11)$ & $0.10(0.07-0.13)$ & $0.05(0.03-0.08)$ & $<0.001$ \\
\hline p value & 0.015 & 0.025 & $<0.001$ & \\
\hline \multicolumn{5}{|c|}{ MaximalC-pep (nmol/L/h) } \\
\hline Before & $1.45(0.8-2.1)$ & $1.8(1.2-2.8)$ & $1.2(0.7-1.8)$ & $<0.001$ \\
\hline After & $0.95(0.5-1.47)$ & $1.65(1.1-2.2)$ & $0.82(0.5-1.33)$ & $<0.001$ \\
\hline $\mathrm{p}$ value & 0.005 & 0.013 & $<0.001$ & \\
\hline MaximalC-pep & & & & \\
\hline
\end{tabular}




\begin{tabular}{|c|c|c|c|c|}
\hline Before & $0.1(0.04-0.21)$ & $0.16(0.10-0.27)$ & $0.08(0.05-0.14)$ & $<0.001$ \\
\hline After & $0.08(0.04-0.14)$ & $0.15(0.09-0.21)$ & $0.07(0.04-0.11)$ & $<0.001$ \\
\hline $\mathrm{p}$ value & 0.031 & 0.029 & 0.019 & \\
\hline \multicolumn{5}{|c|}{ AUCC-pep (nmol/L/h) } \\
\hline Before & $4.4(2.7-6.0)$ & $6.1(4-8.0)$ & $3.5(2.2-5.4)$ & $<0.001$ \\
\hline After & $3.9(2.5-5.2)$ & $5.6(3.6-8.1)$ & $3.0(2.1-4.7)$ & $<0.001$ \\
\hline $\mathrm{p}$ value & 0.153 & 0.294 & 0.047 & \\
\hline \multicolumn{5}{|c|}{ AUCC-pep / AUCglu } \\
\hline Before & $0.09(0.06-1.62)$ & $0.14(0.08-0.23)$ & $0.08(0.05-0.12)$ & $<0.001$ \\
\hline After & $0.08(0.05-1.15)$ & $0.15(0.1-0.21)$ & $0.07(0.05-0.10)$ & $<0.001$ \\
\hline $\mathrm{p}$ value & 0.532 & 0.735 & 0.405 & \\
\hline \multicolumn{5}{|c|}{ C-peptide Index } \\
\hline Before & $0.10(0.02-0.14)$ & $0.11(0.04-0.17)$ & $0.03(0.01-0.10)$ & 0.001 \\
\hline After & $0.12(0.03-0.15)$ & $0.12(0.02-0.27)$ & $0.06(0.02-0.12)$ & 0.323 \\
\hline $\mathrm{p}$ value & 0.348 & 0.201 & 0.368 & \\
\hline \multicolumn{5}{|l|}{ LN HOMA IR } \\
\hline Before & $2.6 \pm 1.1$ & $2.7 \pm 1.2$ & $2.7 \pm 1.3$ & 0.969 \\
\hline After & $2.7 \pm 1.4$ & $2.8 \pm 1.0$ & $2.8 \pm 1.3$ & 0.766 \\
\hline $\mathrm{p}$ value & 0.931 & 0.543 & 0.923 & \\
\hline \multicolumn{5}{|l|}{ Matsuda Index } \\
\hline Before & $15.6(8.8-26.1)$ & $13.5(7.4-25.1)$ & $16.2(9.9-39.3)$ & 0.265 \\
\hline After & 16.6(11.4-32.7) & 13.7(6.4-20.8) & $15.1(7.9-36.8)$ & 0.201 \\
\hline $\mathrm{p}$ value & 0.887 & 0.547 & 0.775 & \\
\hline
\end{tabular}

Note: Data are presented as absolute number, mean $\pm \mathrm{SD}$ or median with interquartile range; $p$ value was derived from the paired t-test or Wilcoxon matched paired test between before and after treatment, and One-Way ANOVA or Kruskal-Waillis test among the three groups. OAD: oral anti-diabetes drugs; AUC: area under the curve; HOMA, homeostasis model assessment; IR: insulin resistance 


\section{Figures}
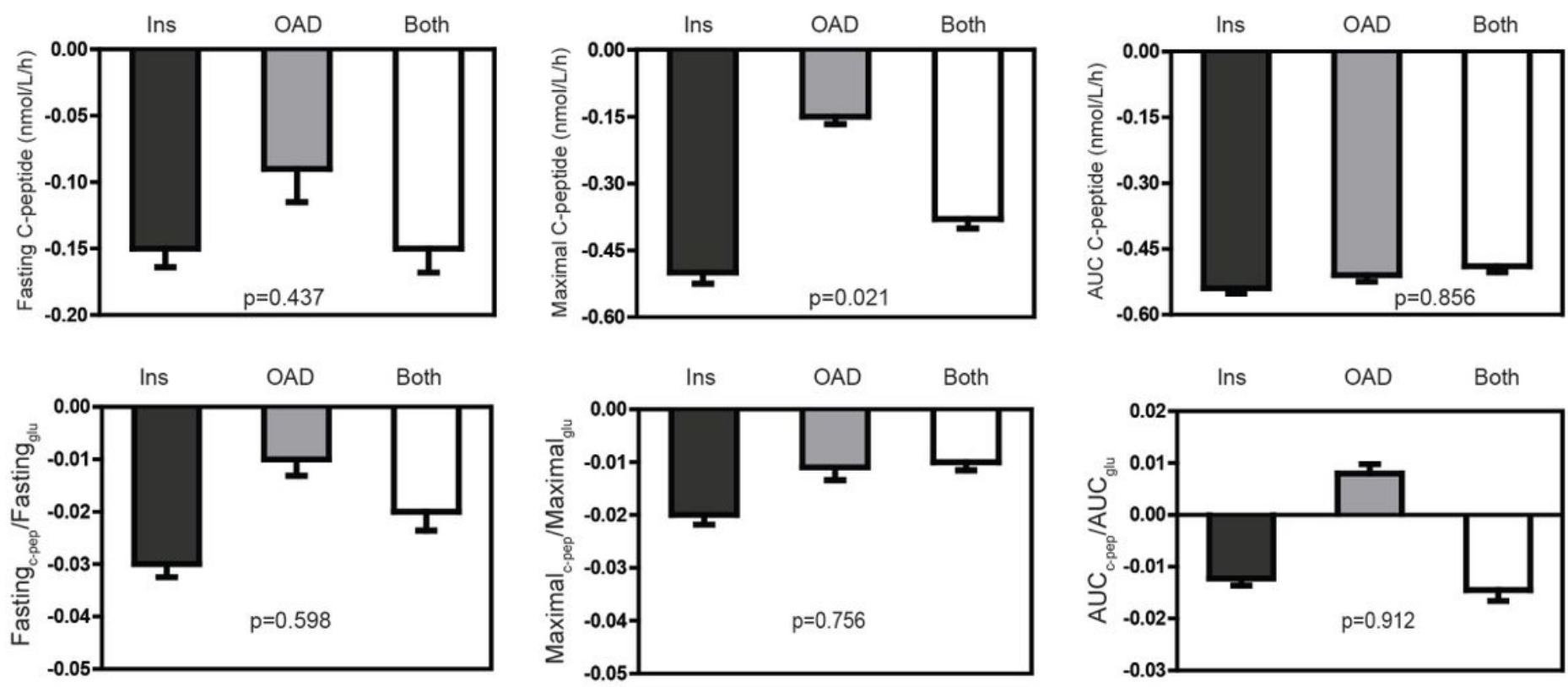

Figure 1

Reductions of different $\beta$-cell function indices between before and after treatment among the three groups. Differences of reduction level among the three groups were derived from the ANCOVA adjusting the baseline fasting C-peptide and metabolic indcies including the age, sex, body-mass index, hypertension, triglycerides and plasma creatinine.

$\Delta$ Insulin - OAD $\mathbf{a}$ Insulin plus OAD
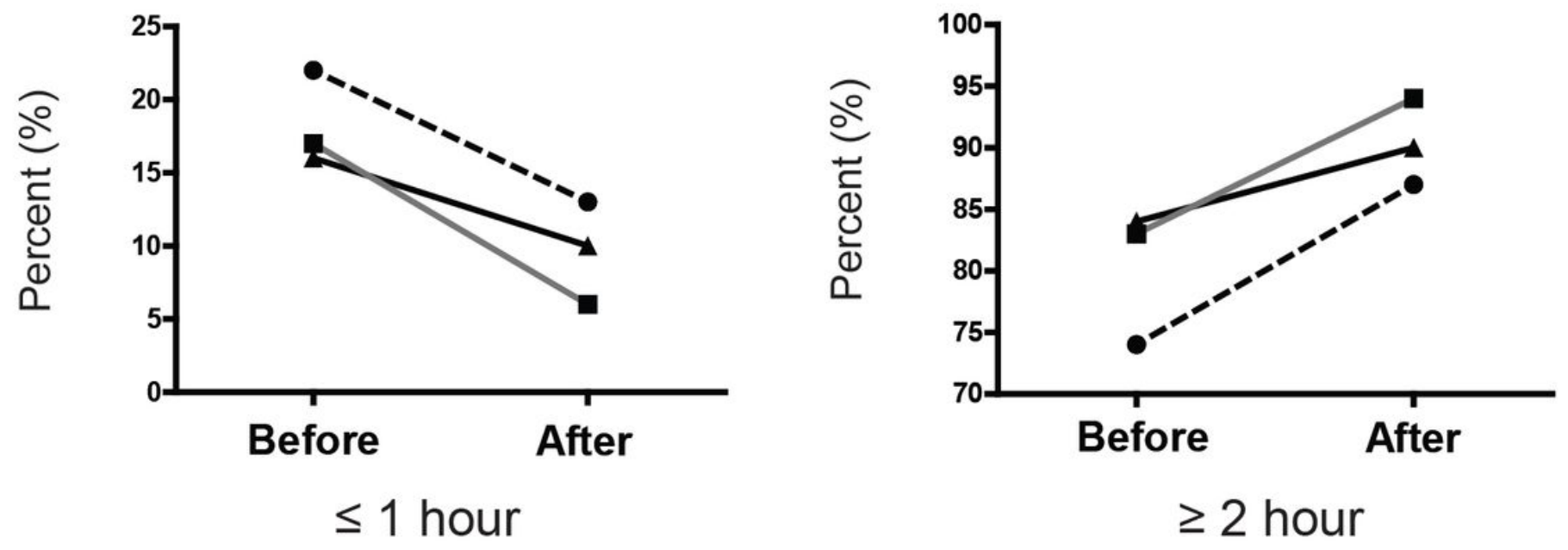
Figure 2

Percentage of insulin peaks before and after treatment among the three groups. Circles, squares, triangles represent insulin group, OAD group and insulin plus OAD group respectively. The left part show the percentage of insulin peak time less than one hour while the right part show the percentage of insulin peak time less superior than one hour. 